\title{
How the CIA backed research on mind control
}

\section{David Dickson reports on recent revelations about the Central Intelligence Agency's support for university research}

IN THE late 1950s and early 1960s, the US Central Intelligence Agency mounted a comprehensive and wellplanned effort to encourage university scientists to carry out research that would, the agency hoped, lead directly to techniques for controlling the human mind.

According to previously classified documents, the agency was responsible for initiating or supporting research that led subsequently to important contributions in various fields of behavioural science, including sociolinguistics, psychotherapy and personality assessment.

And in an effort to legitimise its interest and obtain access to leading investigators, the agency financed a funding organisation that provided grants to a number of prominent members of the scientific community including Carl Rogers, B. F. Skinner and Professor Hans Eysenck--even though the researchers were frequently unaware of the true source of their support.

The details of the CIA's involvement in these fields, described as helping to "liberate the behavioural sciences from the world of rats and cheese", are provided in a book which has just been published in the US by $\mathrm{Mr}$ John Marks, a former Senate aide and State Department official. (The book will appear in the UK later this year.)

Using documents obtained through the Freedom of Information Act, $\mathrm{Mr}$ Marks has put together a detailed picture of how the agency used the academic community in its search for the holy grail: a technique that would provide sufficient manipulation of the human mind to eliminate uncertainty from the intelligence business.

Many of the more bizarre, farcical or outrageous aspects of this pursuit have since received wide publicity. These range from experiments that switched the East coast academic community on to LSD, to the construction of a bugged San Francisco brothel (and included a scheme to make Fidel Castro's beard fall out).

But behind these there was, as $\mathrm{Mr}$ Marks shows, a closely considered plan for deriving, through the extension of conventional research techniques and the often unknowing cooperation of university scientists, the type of information that the CIA could use for controlling the behaviour of its agents and others.

Much of this research was financed through an organisation known as the Society for the Investigation of Human
Ecology, set up at Cornell University in 1955 under the guidance of Dr Harry Wolff, professor of neurology and psychiatry, who was later to become president of the American Neurological Association.

Dr Wolff's aim, which received considerable sympathy in various academic circles of the time, was to provide a framework for the multi-disciplinary study of man in relation to his environment. The CIA's interest was sufficient for it to provide $90 \%$ of the society's funding until, having separated from Cornell in 1957 to obtain "more established stature in the research community", the organisation was folded in the mid-1960s.

Some of the research funded through the society had a direct and obvious relation to the agency's interests. It provided Wolff himself with a research grant of $\$ 74,000$ to study the factors that cause men to defect from their countries and cooperate with a foreign government.

In other cases, the concerns were more basic. Professor Charles Osgood, for example, who had asked the CIA to support his research into the way people in different societies express similar feelings, received $\$ 192,975$ over five years through the society. He later completed his influential work on crosscultural meaning on a grant from the National Institute of Mental Health.

In some cases, the CIA used research grants explicitly to build up the prestige of the Human Ecology Society. Thus the society provided $\$ 26,000$ to Professor Eysenck of London University to support his work on motivation; the agency accepted that the research would have "no immediate relevance to agency needs", but the society took funding credit for nine of his publications in its 1963 report.

"It's news to me", said Professor Eysenck. Often the research workers

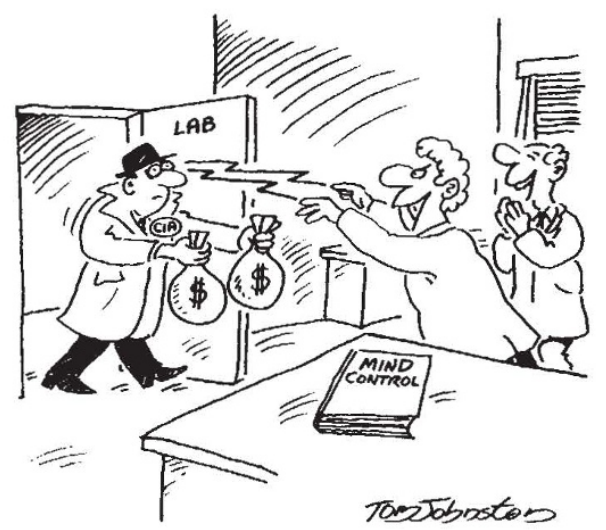

were unaware of the source of the majority of the society's funds; some were told that the money came from rich New York doctors or Texas millionaires. "I don't like secret involvement of any kind. I can't see why it could not have been open and above board", says Professor B. F. Skinner, who received $\$ 5,000$ towards the research leading to his book Freedom and Dignity.

But as well as providing academic respectability, funding of research through the society allowed the CIA legitimately to approach "anyone in the academic community", as one source put it. Thus in a move that $\mathrm{Mr}$ Marks describes as "turning scholars into spies", the society provided $\$ 15,000$ towards a tour of the Soviet Union by ten prominent psychologists (only one of whom knew of the agency's involvement), and CIA officials debriefed the group on its return.

Support for university behavioural research was curtailed in the mid-1960s. However, in contradiction of testimony later given to Senate committees, the research itself was continued, although with a greater emphasis on more direct ways of influencing behaviour, such as inserting electrodes in the brain. (At one point, agency scientists considered the potential of genetic manipulation: "The rest of the world didn't ask until 1976 the type of questions we were facing in 1965", one agency source is quoted as saying.)

Mr Marks admits that much of the research which the CIA sponsored led to important contributions to accepted academic knowledge-possibly because the agency was free to take imaginative leaps denied to more conservative (or more democratic) agencies. But he is uncompromising in criticising the ethical basis under which many of the experiments were carried out. (This was not always the agency's fault; some scientists had to be restrained from taking their experiments on, for example, sensory deprivation to their "terminal" conclusion.)

"We as a country can defend ourselves without sending our own scientists - mad or otherwise - into a hidden war that violates our basic ethical and constitutional principles. . . The time has come for the United States to lead by example by voluntarily renouncing secret government behavioural research". Mr Marks writes in his conclusion.

The Search for the 'Manchurian Candidate': The CIA and Mind Control by John Marks (Times Books. New York, \$9.95). The British edition will be published by Penguin. 